\title{
Hospital Practice
}

\section{Audit of nebuliser use}

\author{
P.E. Williams, S.A. Renowden and M.J. Ward \\ Department of Thoracic Medicine, Llandough Hospital, Penarth, South Glamorgan CF6 1XX, UK.
}

\begin{abstract}
Summary: The use of nebulisers was assessed in four hospitals. Nebulisers were checked in use and medical and nursing staff were interviewed. All but one nebuliser was driven by $100 \%$ oxygen and only 3 of 111 interviewees preferred air for patients with hypercapnia. In 5 of 44 nebulisers in use, water was used as the dilutant. The calculated times for complete nebulisation of the solutions ranged from 3.5 to $117 \mathrm{~min}$. The results of this survey illustrate a need for better education concerning the use of nebulisers in hospitals.
\end{abstract}

\section{Introduction}

Bronchodilators are increasingly being given by nebuliser both in hospital and at home, but the frequency of incorrect use is not well described. We have surveyed the use of nebulisers in the four Cardiff general hospitals.

\section{Methods and results}

In each hospital every ward known to use nebulisers commonly was visited while patients were receiving nebulised treatment. Forty-nine wards were visited of which 26 were surgical, 20 medical, and three paediatric. Forty-four nebulisers in use were checked, of which 40 were in use on medical wards, three on surgical and one on paediatric wards. Sixty-two nursing (sister and staff-nurse) and 49 medical staff (SHO or registrar) were asked questions concerning the way they used nebulisers. In particular, the gas used, its flow rate and volume of bronchodilator to be nebulised was noted.

\section{Type of gas used and flow rate}

All wards used a Hudson Nebuliser (Hudson UpDraft Nebumist disposable nebuliser obtained from Henleys Medical Supplies). All but one nebuliser was driven with $100 \%$ oxygen, the other used an air compressor. Only three interviewees preferred air for patients with hypercapnia. Observed gas flow rates ranged from 1 to 6 litres/min. Nurses and doctors said they would use flow rates between 2 and 10 litres/min (Table I).

Correspondence: P.E. Williams, M.A. M.R.C.P.

Accepted: 21 June 1985
Table I The flow rate of gas to drive nebulisers and the volume of bronchodilator. Percentages show those actually used in the survey and also the way in which nurses and doctors consider they should be given

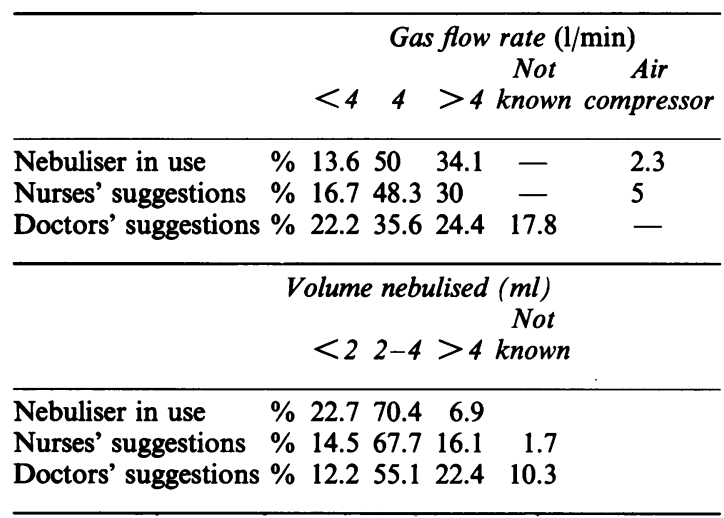

\section{Solutions nebulised}

The volume of bronchodilator solution placed into the nebuliser chamber ranged from 0.5 to $12 \mathrm{ml}$ (Table I). Twenty patients received salbutamol, one ipratropium bromide and one terbutaline. Twenty-two patients had ipratropium bromide mixed with either salbutamol or terbutaline. For five patients the bronchodilator solution was diluted with water. The mean dosage and range of salbutamol, terbutaline and ipratropium bromide placed in the nebuliser were $4.6 \mathrm{mg}(2.5-10 \mathrm{mg}), 17.5 \mathrm{mg}(5-20 \mathrm{mg})$ and $464 \mu \mathrm{g}$ $(125-500 \mu \mathrm{g})$ respectively. 


\section{Discussion}

A nebuliser produces respirable particles of bronchodilators in the form of a mist. Both the size of particles, and the rate of delivery of solution is dependent upon the rate of gas flow used to drive the nebuliser (Clay et al., 1983). Despite the manufacturer's recommendation that a flow rate of 6 to 10 litres/min is required to produce respirable particles of $5 \mu \mathrm{m}$ diameter, lower flow rates of 1 to 4 litres/min were used commonly. Low flow rates generate large particles and although flow rates of 4 and 8 litres/min produce equipotent bronchodilatation in the large airways (Douglas et al., 1985), high flow rates producing small particles of $5 \mu \mathrm{m}$ or less diameter have greater bronchodilator effect in the small airways (Clay et al., 1985).

Low flow rates also produce a slow rate of nebulisation and we have measured that flow rates of $2,4,6$ and 8 litres $/ \mathrm{min}$ nebulise $0.03,0.07,0.18$ and $0.25 \mathrm{ml}$ of solution/min respectively. The calculated times required for the nebulised solution to be given in this survey, therefore, ranged from 3.5 to $117 \mathrm{~min}$. It is doubtful whether any patient would persist with nebulised treatment for more than $30 \mathrm{~min}$. Therefore, we would suggest the use of the higher flow rates to produce smaller particles and enable shorter nebulisation times, with air being used for patients at risk of developing hypercapnia.

A proportion of the solution remains in the nebuliser chamber after treatment, and for the Hudson nebuliser this 'dead space' is $0.5 \mathrm{ml}$. The volumes of solution put into the nebuliser varied between $0.5 \mathrm{ml}$ and $12 \mathrm{ml}$, and it is likely, therefore, that patients given small volumes, such as $0.5 \mathrm{ml}$, received little, if any, bronchodilator.

It is worrying that so many nebulisers were driven with $100 \%$ oxygen and that only three interviewees expressed a preference for using air in patients with hypercapnia. We have sampled and measured the oxygen tension of gas in the pharynx of subjects given nebulised treatment using the Hudson nebuliser, with $100 \%$ oxygen. Flow rates of 4 and 8 litres $/ \mathrm{min}$ produced an oxygen tension of $30-33 \%$ and $40-44 \%$,

\section{References}

CLAY, M.M., PAVIA, D., NEWMAN, S.P. \& CLARKE, S.W. (1983). Factors influencing the size distribution of aerosols from jet nebulisers. Thorax, 38, 755 .

CLAY, M.M., PAVIA, D. \& CLARKE, S.W. (1985). Does nebulised bronchodilator aerosol droplet size matter? Thorax, 40, 222.

DOUGLAS, J.G., LESLIE, M.J., CROMPTON, G.K. \& GRANT, I.W.B. (1985). Is the flow rate used to drive a jet nebuliser clinically important? British Medical Journal, 290, 29.

ESCHENBACHER, W.L., BOUSHEY, H.A. \& SHEPPARD, D. (1984). Alteration of osmolality of inhaled aerosols cause bronchoconstriction and cough, but absence of a permeant respectively. The use of oxygen to drive nebulisers in patients with carbon dioxide retention may exacerbate hypercapnia, and previous workers have recommended that, if this be done, then the time for nebulisation should be less than 10 min (Gunawardena et al., 1984). Only $14 \%$ of patients in this survey had completed nebulisation within this time.

The amounts of fluid nebulised in $10 \mathrm{~min}$ using the Wright's, Mini-neb Inspiron, Acorn OEM, Hudson and Turrett nebulisers are $0.4,0.9,0.6,0.4$, and $0.4 \mathrm{ml}$, respectively, at 4 litres $/ \mathrm{min}$ and $414 \mathrm{kPa}$ driving gas flow rate and pressure (Wilson $e t$ al.), this being the normal hospital pipeline pressure. At 8 litres $/ \mathrm{min}$ flow rate, at the same pressure, the respective amounts nebulised are $0.7,1.2,1.7,1.0$ and $1.0 \mathrm{ml}$. At these flow rates the Acorn OEM, and the Mini-neb Inspiron devices nebulise fluid most quickly and should, thus, be the preferred nebulisers if hospital pipeline oxygen, rather than air, is used as the driving gas.

Water was used to dilute bronchodilator solutions in five patients. Although no adverse reaction was noticed in this survey, decreasing tonicity of the solution may lead to bronchospasm (Eschenbacher et al., 1984). A common treatment was salbutamol and ipratropium bromide given as a mixture, and we find this unusual as the two drugs have been administered by separate nebulisation in previous work (Ward et al., 1981).

It appears that education concerning the correct use of nebulisers is much needed. Characteristics of the nebuliser used, such as the 'dead space' volume of the nebulisation chamber, and the rate of nebulisation in $\mathrm{ml} / \mathrm{min}$ at the different driving gas flow rates, should be known. The instructions to nursing staff concerning the volume to be nebulised, the gas to be used, its flow rate and the use of dilutants should be written down in the form of a detailed prescription as occurs with other drug therapy.

\section{Acknowledgement}

We thank Dr I.A. Campbell for his help in preparing this manuscript. anion causes cough alone. American Review of Respiratory Disease, 129, 211.

GUNAWARDENA, K.A., PATEL, B., CAMPBELL, I.A., MCDONALD, J.B. \& SMITH, A.P. (1984). Oxygen as a driving gas for nebulisers: safe or dangerous? British Medical Journal, 288, 272.

WARD, M.J., FENTON, P.H., RODERICK SMITH, W.H. \& DAVIES, D. (1981). Ipratropium bromide in acute asthma. British Medical Journal, 282, 598.

WILSON, R.S.E., STEVENTON, R.D. \& PHILLIPS, L.A. Nebuliser systems and the domiciliary administration of bronchial active drugs. (Obtained from Allen \& Hanburys Ltd). 